sidence followed about 20,000 years of relative stability; after a further 5,000 years a greater change occurred. Dr. C. Downie described symmetrical cycles in the Kimeridge Clay consisting of clay-bituminous shale-oil shale-bituminous marl-coccolith limestone and the $r \theta$ verse sequence. These were probably attributable either to climatic (wet-dry) or tectonic (regression-transgression) changes. Dr. Downie estimated that the 170-200 cycles had developed during 6-8 million years, indicating a periodicity of between 30,000 and 47,000 years.

Notable points in the discussion of the papers presented during the symposium concerned whether the characteristic asymmetry of many sedimentary cycles necessarily implied fluctuating rates of change of the controlling mechanism, whother tectonic or eustatic, and the likely amount and cause of changes of sea-level in the Lias. Mr. W. A. Cummins raised the interesting point that major turbidite formations in the geosynclinal facies of the Anglo-Welsh Silurian appeared to correlate with likely times of high sea-level in the shelf facies.

The problem of terminology was, perhaps inevitably, left unresolved. It was instructive to have Mr. I. F. Sime (Ministry of Aviation) define cycles as a series of occurrences in which conditions at the end of the series are the same as at the beginning-in recurrent cycles all series must be exactly similar. They could be represented mathematically by a sine wave, or related to a sine wave by a Fourier series. Alternatively impulses, which might be periodic or random, could trigger off successions of events which would be varied by local conditions, so that the series would not necessarily be similar in every case. In the limit, the series could be represented by one component.

A. Hatiam

E. K. WALTON

\title{
SOIL EROSION BY WATER
}

\begin{abstract}
THE realization of the urgent need of producing more food to meet the rapidly increasing requirements through the growth in world population has directed much attention to the question of controlling soil erosion. Erosion is a normal process and has indeod provided the parent material of soils on which we are dependent for crops. But it is clearly desirable to prevent or reduce the erosion of fertile soils in existence and serious losses of soils are undoubtedly attributable to the action of man. Soil conservation services have been set up in many countries with the view of persuading farmers to give up methods that may accelerate erosion and to adopt practices that will protect the soil and increase productivity.

The reason for erosion is quite well understood. When vegetation cover is removed, rain drops can move particles of soil and when the rainfall is heavy and greater than the rate of infiltration the excess water transports the soil particles. The eroding and transporting are functions of the velocity of the water movement and the properties of the soil particles. When the velocity increases from 1 to $2 \mathrm{ft}$. per sec, eroding power is increased 4 times and transporting power 32 times. Even relatively stable aggregates are dispersed by impact during a storm and can seal the soil surface; this starts run-off by the path of least resistance so that surface flow with fine particles in suspension moves into small channels which may develop into large gullies. The eroded soil may settle at distances
\end{abstract}

depending on particle size or be carried out to sea; some may be deposited in drainage channels or reservoirs or on growing crops and cause great damage. There are certain principles in the control of erosion which are easy to grasp. Keeping the soil covered with vegetation or with a mulch of residues obviously protects the surface from the impact of falling drops and improves the infiltration. Retention terraces, contour planting or strip cropping can prevent run-off or reduce its velocity to a balance with infiltration. Moreover, machines are available for earth-moving and seed-sowing in accordance with the best combined measures of husbandry and control.

These techniques have been proved in many landsthe United States, parts of Africa, Australia and New Zealand, Israel-and many bulletins on the subject have been published. Numerous specialists in the work have contributed information to the Agricultural Engineering Branch of the Water Development Division of the Food and Agriculture Organization of the United Nations, and in a recent paper, presented at an open meoting of the Institution of Agricultural Engineers at the Royal Society of Arts, on January 15, M. E. B. Neal summarizes the present position*. It contains a comprehensive list of services concerned with conservation and of publications on the subject.

A. M. Бмттн

* Journal of the Institution of Agricultural Engineers, 19, No. 1, 4 (1983).

\section{INFLUENCE OF THE EARTH'S CORE ON THE ORIGIN AND EVOLUTION OF LIFE}

\author{
BY ROBERT J. UFFEN \\ University College of Arts and Science, University of Western Ontario, London, Ontario
}

T has generally been held that natural radiation-induced mutations have not played any significant part in biological evolution. However, the discovery of geomagnetically trapped, charged particle belts around the Earth of intensity perhaps as high as $100 \mathrm{r}$./h (refs. I and 2) raises the possibility that the Earth's surface may have been exposed in the past to ionizing radiation many times greater than previously envisaged. Palæomagnetic data $^{3}$ indicate that the geomagnetic field intensity must have been reduced to zero for intervals of several thousand years ${ }^{4}$ which, while almost instantaneous on the geological time-scale, would encompass many generations of living organisms. During these intervals the trapped corpuscular radiation may have spilled on to the Earth, and the solar wind would have been able to bathe the Earth, producing mutation rates many times greater than the spontaneous rates and thus capable of being a major influence in evolution in the presence of the environmental selection pressures of those times.

It is the purpose of this article to set forth qualitatively, the hypothesis that the thermal history of the Earth has determined the origin and development of its core, which has been a major factor in ovolution through its control of the main geomagnetic field ${ }^{5}$ and consequently of the charged particles which have been able to reach the Earth.

The argument involves the following process within the Earth: (a) The creation of a protocrust, protomantle and protocore by partial melting of the iron and silicates of the interior due to radioactive heating. The temperature 